\title{
Assessing the sustainability performances of industries
}

\author{
Carin Labuschagne $^{\mathrm{a}}$, Alan C. Brent ${ }^{\mathrm{a}}$ and Ron P. G. van Erck ${ }^{\mathrm{b}, \mathrm{a}}$ \\ a Department of Engineering and Technology Management, University of Pretoria, \\ Room 4-12, Engineering 2, Pretoria 0002, South Africa \\ ${ }^{\mathrm{b}}$ Department of Technology Management, Technical University Eindhoven, Eindhoven, \\ The Netherlands
}

\section{Abstract}

Business sustainability entails the incorporation of the objectives of sustainable development, namely social equity, economic efficiency and environmental performance, into a company's operational practices. Companies that compete globally are increasingly required to commit to and report on the overall sustainability performances of operational initiatives. The current indicator frameworks that are available to measure overall business sustainability do not effectively address all aspects of sustainability at operational level, especially in developing countries such as South Africa. Social criteria, specifically, do not receive due considerations. This article proposes a new framework to assess the sustainability of operations in the manufacturing sector.

\section{Article Outline}

1. Introduction

2. Review of current integrated sustainability frameworks

2.1. Global Reporting Initiative

2.2. United Nations Commission on Sustainable Development Framework

2.3. Sustainability Metrics of the Institution of Chemical Engineers

2.4. Wuppertal Sustainability Indicators 
3. Proposed framework to assess the sustainability of operational initiatives

3.1. Institutional sustainability and business strategy

3.2. Corporate social investments and the sustainability of business initiatives

3.3. Criteria for economic sustainability

3.4. Criteria for environmental sustainability

3.5. Criteria for social sustainability

3.5.1. Internal human resources

3.5.2. External population

3.5.3. Stakeholder participation

3.5.4. Macro-social performance

4. Appropriateness of the proposed framework criteria for project life cycle management in the South African process industry

5. Identifying measurable indicators for the proposed criteria

6. Conclusions and the way forward

References

\section{Introduction}

The last decade has seen an increased pressure to broaden the accountability of companies (and industry as a whole) beyond economic performance, for shareholders, to sustainability performance for all stakeholders [1]. The concept of business or corporate sustainability has therefore grown in recognition and importance. Business sustainability can be defined as "adopting business strategies and activities that meet the needs of the enterprise and its stakeholders today while protecting, sustaining and enhancing the human and natural resources that will be needed in the future" [2].

The concept of sustainability is understood intuitively, but it remains difficult to express it in concrete, operational terms [3]. A systems approach consistent with the basic principles and requirement for sustainability has been proposed to consider strategic sustainable development planning at a company level [4]. The approach thereby attempts to:

- Cover social and ecological sustainability on the basic principle level, 
- Translate the definition of sustainability to the institutional level,

- Manage the strategic perspective through a step-by-step approach whereby economic performance is taken into account regarding short-term as well as long-term risks,

- Advocate the development of indicators that have this perspective, and

- Show how various initiatives on this arena relate to such a sustainability perspective.

However, the proposed synergy of the available tools does not adequately assist industry decision-makers (at company management level) who are required to assess and evaluate their operations in terms of internal and external impacts. Optimal decisions can only be made when the economic, social and environmental consequences are taken into consideration [5]. A definite need has therefore been identified to develop a comprehensive framework of sustainability criteria that focus on operational practices in the manufacturing sector, and more specifically the assessment of the sustainability performances of technological developments during project management [6].

Since the United Nations and national governments worldwide have been the driving force behind sustainable development, most frameworks that have been developed to assess sustainability have subsequently focused on a national, regional or community level [7, 8 and 9]. The frameworks typically address the three generally accepted dimensions of sustainable development (economic, environmental, and social), while some frameworks also include a fourth dimension, namely "institutional”, as introduced by the United Nations approach [7]. Far less work has been done on a company level to develop and implement sustainability performance assessment practices [9]. An analysis of more than 50 business-related initiatives revealed that frameworks do exist to assess business sustainability but "in most of the (six) integrated (sustainability measurement) initiatives the primary focus is the environmental dimension” [10]. Furthermore, the focus of the available integrated sustainability frameworks is mostly on a product level within an organization [11], with the Global Reporting Initiative (GRI) the only recognized international initiative that focuses on reporting the sustainability of the entire organization [12]. 
This paper proposes a comprehensive framework of sustainability criteria that can be used to assess the sustainability of projects, technologies, as well as the overall company sustainability. The framework is based on published approaches and impact assessment guidelines, but specifically addresses the needs of the South African process industry, i.e. within a developing country context, and focuses strongly on operational initiatives. The paper further reviews possible approaches (and experienced complications) to translate the criteria into measurable indicators for performance measurements.

\section{Review of current integrated sustainability frameworks}

Current integrated frameworks to assess sustainability, whether nationally, internationally, locally or company focused, have been reviewed to determine relevant aspects (or criteria) that should be considered when assessing industry sustainability. The selection of frameworks that were reviewed was based on the following:

(a) The indicator framework includes a set of (measurable) indicators.

(b) The indicator framework addresses all three dimensions of sustainability, i.e. environmental, social, and economic indicators are part of the framework.

(c) The indicator framework has a wide focus, i.e. at a national, community or company level. Product-only focused frameworks were not considered.

(d) The indicator framework is not strongly based on another framework or guidelines, e.g. frameworks have been proposed at a country level that are slight modifications of the United Nations framework [7].

The following frameworks were subsequently reviewed:

- Global Reporting Initiative (GRI).

- United Nations Commission on Sustainable Development Framework.

- Sustainability Metrics of the Institution of Chemical Engineers.

- Wuppertal Sustainability Indicators. 


\subsection{Global Reporting Initiative}

In 1997, the United Nations Environment Programme (UNEP) together with the United States non-governmental organization, Coalition for Environmentally Responsible Economics (CERES) launched the GRI with the goal of "enhancing the quality, rigour and utility of sustainability reporting" [12]. Reporting is therefore the strong focal point of the guidelines. The GRI uses a hierarchical framework in three focus areas, namely social, economic, and environmental ( Fig. 1). The hierarchy consists of categories, aspects, and indicators. The guideline contains more than 100 indicators. However, not all the indicators are easy to evaluate and no guidance is given on how to choose between the indicators [9]. The guideline does, however, indicate what should be considered at a lower level, i.e. operational or project level within the company, especially if the company reports on sustainability using the GRI principles.

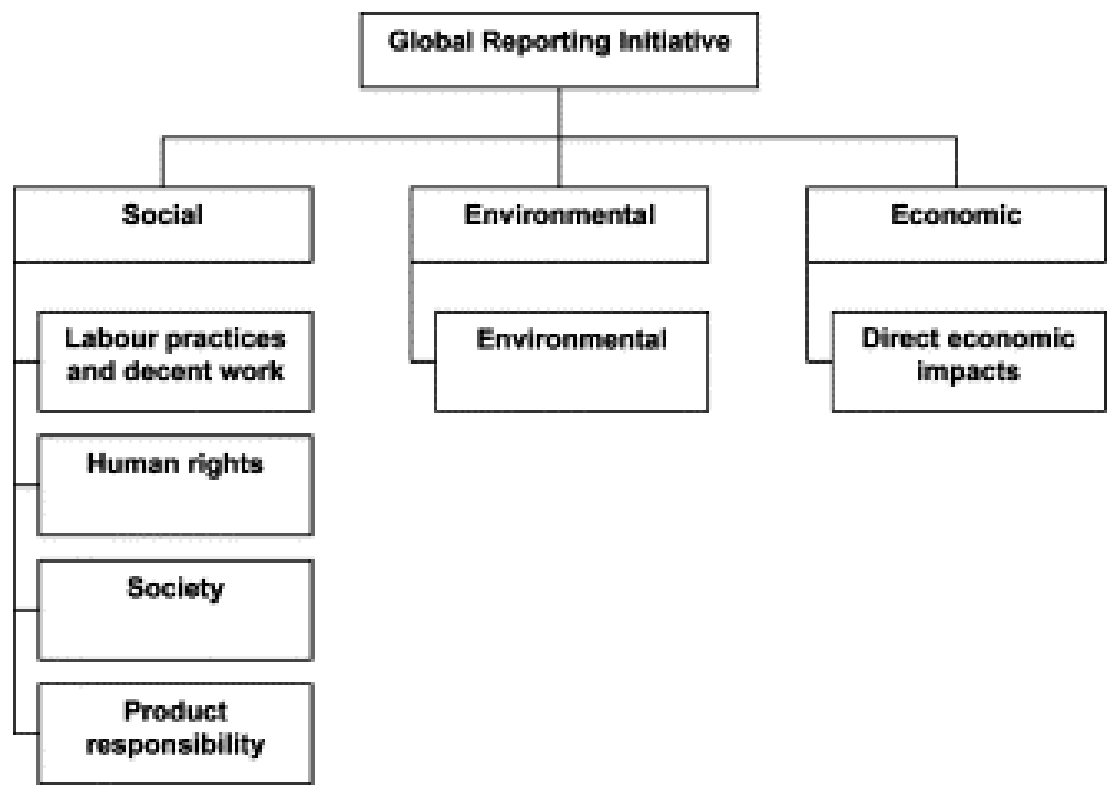

Fig. 1. The hierarchical structure of the Global Reporting Initiative (GRI) framework.

\subsection{United Nations Commission on Sustainable Development Framework}

The United Nations Commission on Sustainable Development (CSD) constructed a sustainability indicator framework for the evaluation of governmental progress towards sustainable development goals. A hierarchical framework groups indicators into 38 subthemes and 15 main themes, that are divided between the four aspects of sustainable 
development (Fig. 2) [7]. The main difference between this framework and the GRI, for example, is the fact that it addresses institutional aspects of sustainability. The framework has been used as a basis by numerous developing nations [8]. The aspects addressed by the framework are not all relevant to the business community, and definitely not on an operational and project level. However, the framework provides insight into what sustainability entails on a national level, as well as areas in which business can make a contribution.

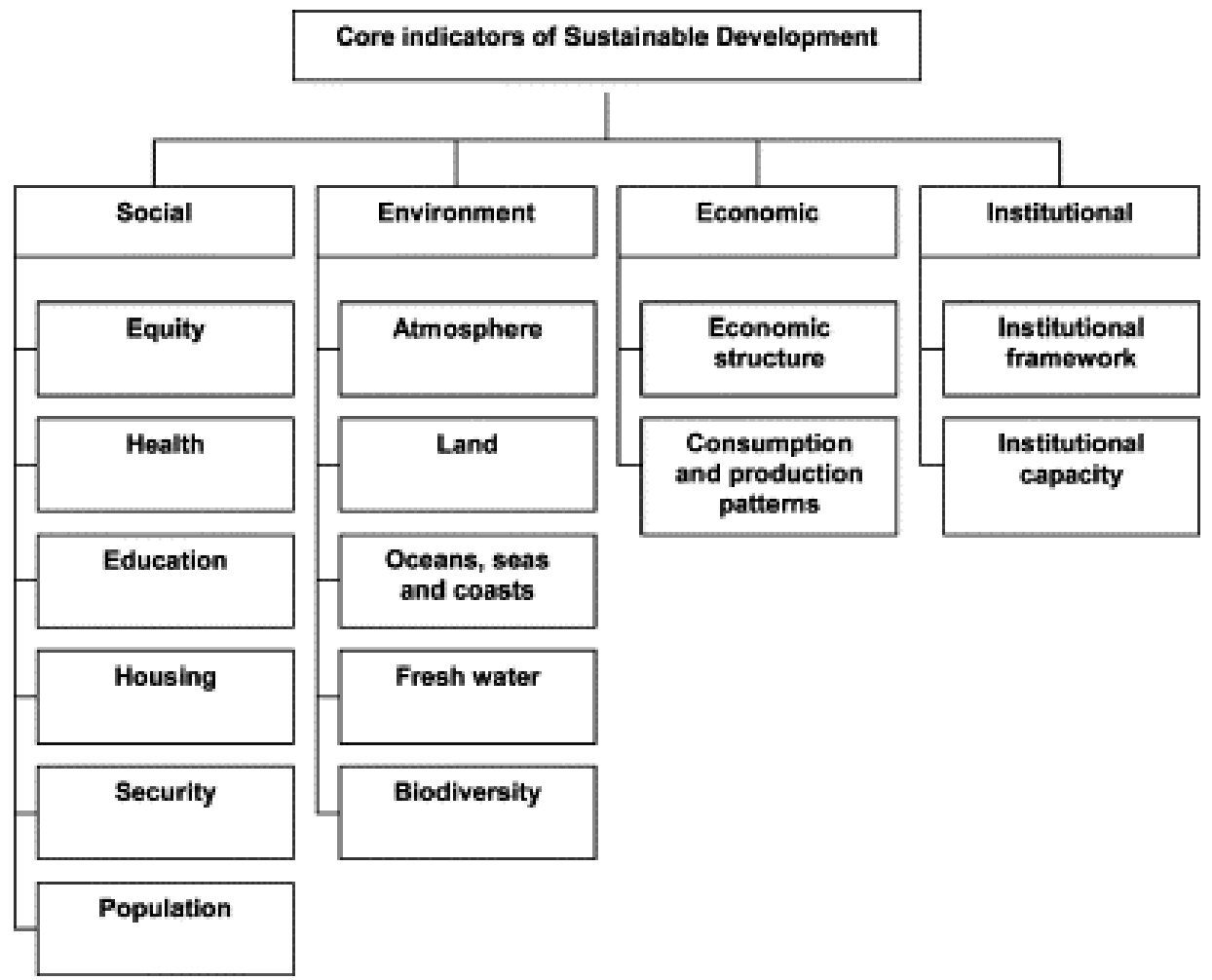

Fig. 2. The United Nations Commission for Sustainable Development (CSD) theme indicator framework.

\subsection{Sustainability Metrics of the Institution of Chemical Engineers}

The Institution of Chemical Engineers (IChemE) published a set of sustainability indicators in 2002 to measure the sustainability of operations within the process industry (Fig. 3). The IChemE provides standard reporting forms and conversion tables [13]. This framework is less complex and impact oriented. However, the framework strongly favors 
environmental aspects, as well as quantifiable indicators that may not be practical in all operational practices, e.g. in the early phases of a project's life cycle [14].

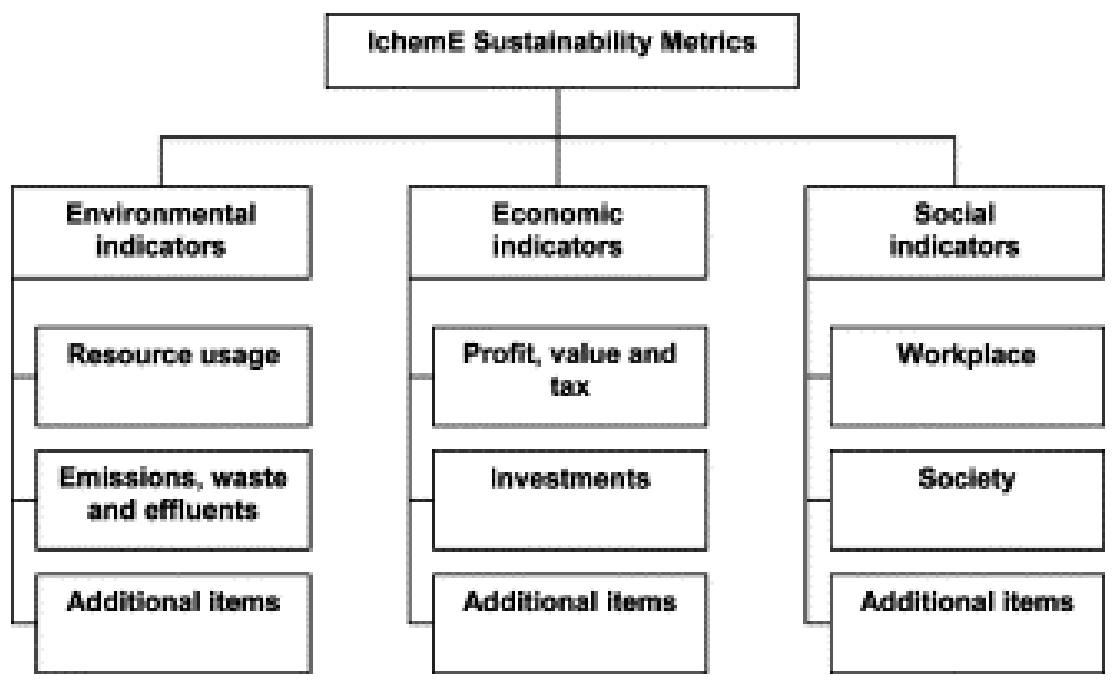

Fig. 3. The Institute of Chemical Engineers (IChemE) sustainability metrics.

\subsection{Wuppertal Sustainability Indicators}

The Wuppertal Institute proposed indicators for the four dimensions of sustainable development, as defined by the United Nations CSD, together with interlinkage indicators between these dimensions (Fig. 4) [15]. These indicators are applicable both on a macro-(national) and micro-(business) level. The approach used to address business social sustainability is worth noting; the United Nations Development Programme (UNDP) Human Development Index has been adapted to form a Corporate Human Development Index. The Corporate Human Development Index consists of three main components:

- Quality of industrial relations and labor conditions,

- Education, i.e. input and maintenance of human capital, and

- Income level and distribution. 


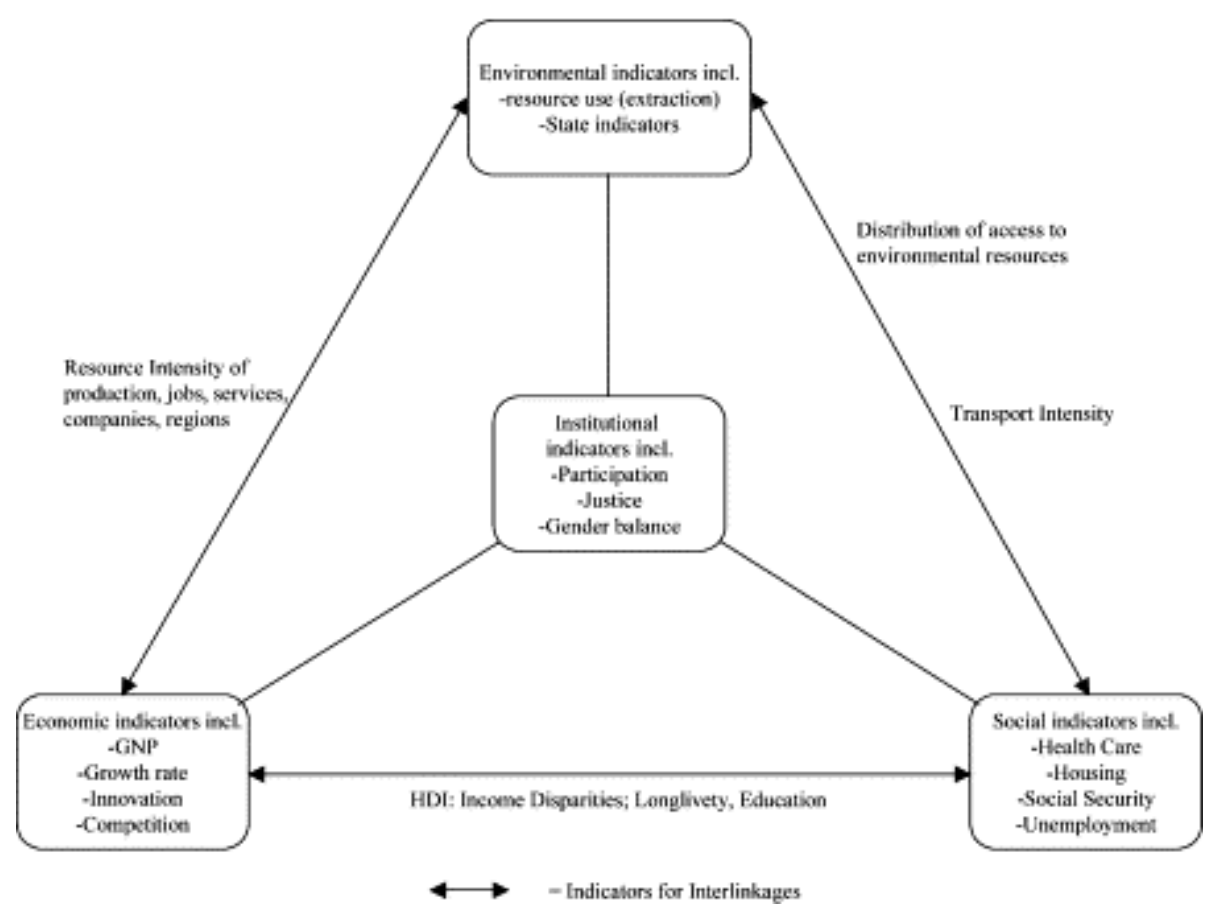

Fig. 4. The Wuppertal sustainable development indicator framework: sectoral and interlinkage indicators [15].

\section{Proposed framework to assess the sustainability of operational initiatives}

\subsection{Institutional sustainability and business strategy}

In order to propose a modified framework it is necessary to determine whether sustainability should be measured in three or four dimensions. The fourth dimension, institutional sustainability, has been proposed by the United Nations in Chapter 8 of Agenda 21 [16]. Chapter 8, which is considered to be the "core” institutional chapter [16], calls for, amongst others, the adoption of national strategies of sustainable development and the integration of socio-economic and environmental aspects in decision-making. The United Nations CSD addressed this dimension by dividing it into two themes: institutional framework and institutional capacity [7 and 16]. Based on the United Nations description of this dimension, companies can address institutional sustainability at a strategic level by: 
(a) Mentioning and incorporating sustainability principles within business strategies (i.e. vision, mission, business goals, etc.) in line with those of national and international governments.

(b) Openly acknowledging support for global agreements.

(c) Including external sustainable development objectives in internal research and development.

(d) Allocating funds to address sustainability issues beyond the immediate control of the company.

The manifestation of institutional sustainability on a strategic level within a business (or industry) can therefore be seen as a prerequisite for sustainable operations, projects or even corporate sustainability. The first level of the proposed sustainability assessment framework is thus referred to as the "corporate responsibility strategy”. It implies that a prerequisite for all sustainability is a strategy that accepts the company's responsibility and its vital role in every society it operates in and also in the global environment (see Fig. 5 in Section 3.2). The sustainability of all internal initiatives is therefore only evaluated in terms of the remaining three dimensions.

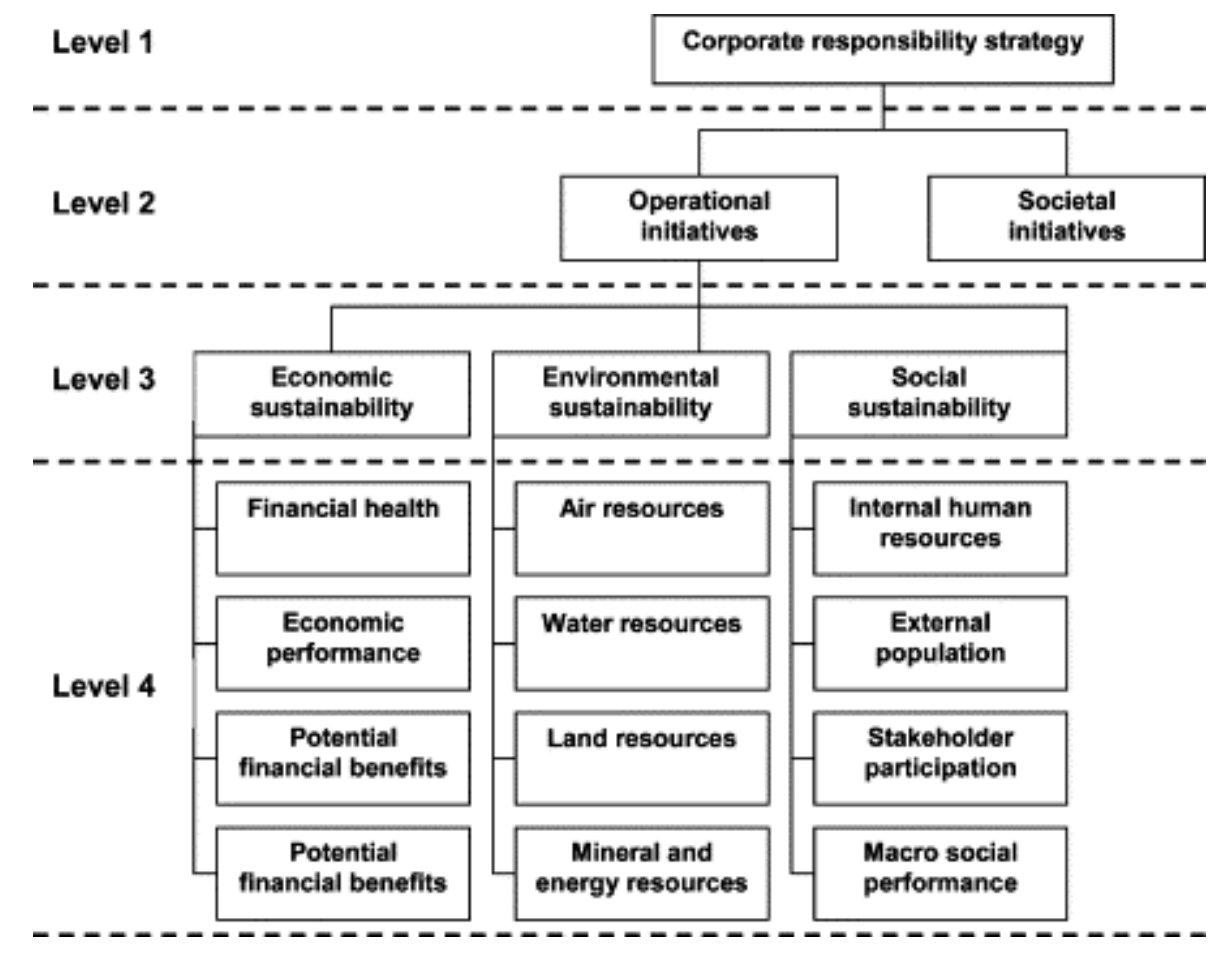

Fig. 5. Levels 1-4 of the proposed operational sustainability framework. 


\subsection{Corporate social investments and the sustainability of business initiatives}

The review of the sustainability assessment frameworks and the sustainability or corporate social responsibility (CSR) reports of companies has shown that corporate social investment should not be confused with, or interpreted as, the only dimension of social sustainability of an industry. The Prince of Wales Institute [17] states that corporate responsibility should aim to make a positive contribution in the following three areas of influence:

(a) Core business activities by ensuring a responsible implementation thereof.

(b) Poverty-focused social investment and philanthropy programs.

(c) Institution building and public policy dialogues by getting involved.

A corporate responsibility strategy (as discussed in Section 3.1) should thus be evident in sustainable business activities as well as in corporate social investments and programs. Corporate social investment (CSI) and CSR focused projects do contribute to the overall sustainability of the company and is evaluated as such [12], but is not part of a company's core business (or operational) activities. The social sustainability of core business activities should thus not be evaluated in terms of the CSI programs of the whole company. In order to ensure that this distinction is made in the proposed framework, level 2 of the framework defines the corporate strategy into two distinct parts: operational initiatives, which include core business activities, projects, etc., and societal initiatives, which refer to CSI and CSR programs ( Fig. 5). Operational initiatives should be evaluated in terms of the three dimensions of sustainability (see Section 3.1) at level 3 of the proposed framework. Level 4 in Fig. 5 contains the main criteria, which should be considered within each dimension. The framework consists of six levels, and levels 4-6 are discussed in greater detail.

\subsection{Criteria for economic sustainability}

The various frameworks that were reviewed do not address economic sustainability in the same context. The GRI defines economic sustainability as concerning “an organisation's impacts on the economic circumstances of its stakeholders and on economic systems at the local, national and global levels” [12]. The GRI is thus predominantly concerned 
with the external impacts of a business on economic systems. The United Nations, Wuppertal Institute, and the IChemE frameworks have an internal focus, e.g. the United Nations and Wuppertal frameworks consider economic performance (of a nation) in terms of gross national product or gross domestic product per capita. Consequently, it is required to stipulate whether an internal or external focus is followed for the economic dimension of the proposed framework.

The Caux Round Table's principles for business stated that although survival on its own is not a sufficient goal, a business must at all times maintain its own economic health and viability [18]. Also, it has been stated that the first step for businesses, who are serious about social responsibility, is to stay in business [19]. Companies survive on the long term through their ability to be profitable and unviable businesses can make no contribution to the economic systems on a local, national or global level [20]. Internal operational initiatives directly contribute to the overall profitability of a company. Furthermore, the proposed framework is aimed at assessing the economic sustainability of a company; therefore, the focus of the economic sustainability measurement framework is internal, while external economic contributions (or burdens) are allocated to social sustainability, i.e. as external socio-economic aspects. The IChemE and United Nations approaches have been used as a basis to define the criteria relevant for this dimension, for which the aim is to evaluate the business' short- and long-term financial stability and survival capabilities. The following four criteria are used for this purpose: (a) Financial health: The criterion entails those aspects assessing the internal financial stability of a company and includes traditional financial sub-criteria such as profitability, liquidity, and solvency.

(b) Economic performance: The criterion assesses the company's value as perceived by shareholders, top management, and government and includes sub-criteria such as share profitability, contribution to gross domestic product (GDP) as well as market share performance.

(c) Potential financial benefits: The criterion assesses financial benefits other than profits, e.g. national and/or international subsidies based on the environmental, social, and/or technological improvements due to business initiatives. For example, projects that are 
potentially eligible for clean development mechanism (CDM) funding under the Kyoto Protocol.

(d) Trading opportunities: The criterion assesses the vulnerability of the company's trade network as well as the risks it is exposed to by the network it is embedded in by considering the number of national and/or international companies in the trade network.

\subsection{Criteria for environmental sustainability}

In the South African context, the national government has clearly indicated the important criteria within the environmental dimension [21]. Using the priorities of the national government as a guideline, criteria for the assessment of environmental sustainability of projects have been developed for the South African process industry [14]. These criteria are similar to those that have been proposed to evaluate the clean development mechanism (CDM) projects within South Africa [22], and to assess the overall impacts of life cycle systems in the South African context [23]. It has an external focus with four natural resource groups as main criteria:

(a) Air resources: The criterion assesses a company's contribution to regional air quality effects (e.g. toxicity, acidification, etc.) as well as to global effects such as global warming and stratospheric ozone depletion.

(b) Water resources: The criterion assesses the availability of clean and safe water by focusing on a company's impacts on the quantity and quality of water, i.e. water usage and releases of water effluents and pollutants.

(c) Land resources: The criterion assesses a company's impacts on the quantity and quality of land resources, including sub-criteria of land-usage and transformation (and subsequent impacts on biodiversity), direct and indirect releases of soil pollutants, etc. (d) Mineral and energy resources: The criterion assesses a company's contribution to the depletion of non-renewable mineral and energy resources.

Although the possible causes and effects of industry activities on the natural state of the four resource groups have been well documented, it must be noted that there is, as yet, no consensus on a consistent methodology to measure these causes or effects. However, many quantitative and qualitative methodologies have been proposed [23, 24 and 25]. The strive towards arriving at a consensus is highlighted in the ongoing work of the Life 
Cycle Impact Assessment (LCIA) workgroup of the United Nations Environmental Programme (UNEP) global life cycle initiative [26].

\subsection{Criteria for social sustainability}

Businesses are increasingly paying more attention to the social dimension of sustainable development, mainly due to an experienced shift in stakeholder pressures from environmental- to social-related concerns [27]. However, "far less work has been done on social sustainability, as it applies to business" [28]. Since the aim with the framework is to evaluate the sustainability performances of operational initiatives, the social dimension of the proposed framework is concerned with the company's impacts on the social systems in which it operates, as well as the company's relationship with its various stakeholders.

The information reviewed in the sustainability frameworks was not regarded as efficient; therefore, additional Social Impact Assessment (SIA) guidelines and frameworks, as well as literature on CSR have been reviewed:

(a) European framework on corporate social responsibility [29].

(b) Interorganizational Committee on Guidelines and Principles for SIA [30].

(c) Socio-economic impacts for climate change mitigation [31].

(d) South Sydney Council: SIA Checklist [32].

(e) SIA categories for development projects in South Africa [33].

(f) SIA categories for CDM projects in South Africa [22].

(g) Classifications of social impacts according to Vanclay [34].

(h) Dow Jones Sustainability Index [35].

The social criteria that are addressed by the various frameworks, guidelines and classifications have been compared and are summarized in Table 1. As a first observation, stakeholders exist within and outside the company [36]. Social business sustainability therefore has definite internal and external focuses. The internal focus concerns the health and well being of employees, disciplinary practices and equity and human rights aspects in employee sourcing. Training and development opportunities for 
employees are also included. The external focus concerns the impacts of the operational initiative on three different levels of society: local community, regional and national level. In certain cases these impacts include those on or contributions to a community, region or nation's economic activities. In the case of the GRI, these impacts are addressed as economic sustainability criteria. The second observation is the vital role played by communication and interaction with stakeholders within social sustainability. Stakeholders and society have been defined as two of the five key corporate sustainability performance principles [35]. Stakeholder participation is also a social sustainability criterion within most of the frameworks or guidelines developed with a business perspective, e.g. GRI, IChemE, and the Dow Jones Sustainability Group Index. Based on the analysis, a framework consisting of four main criteria is proposed to measure social sustainability of operational initiatives ( Fig. 6). 
Table 1. Analysis of the social criteria addressed by current frameworks and guidelines

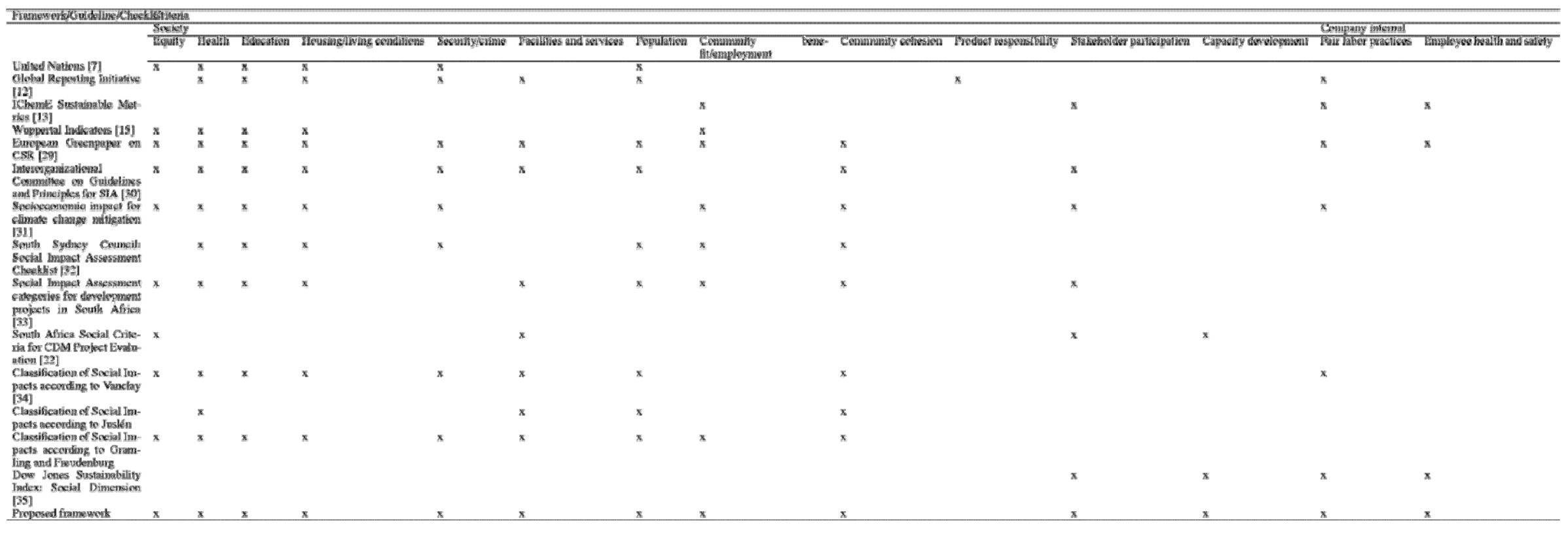




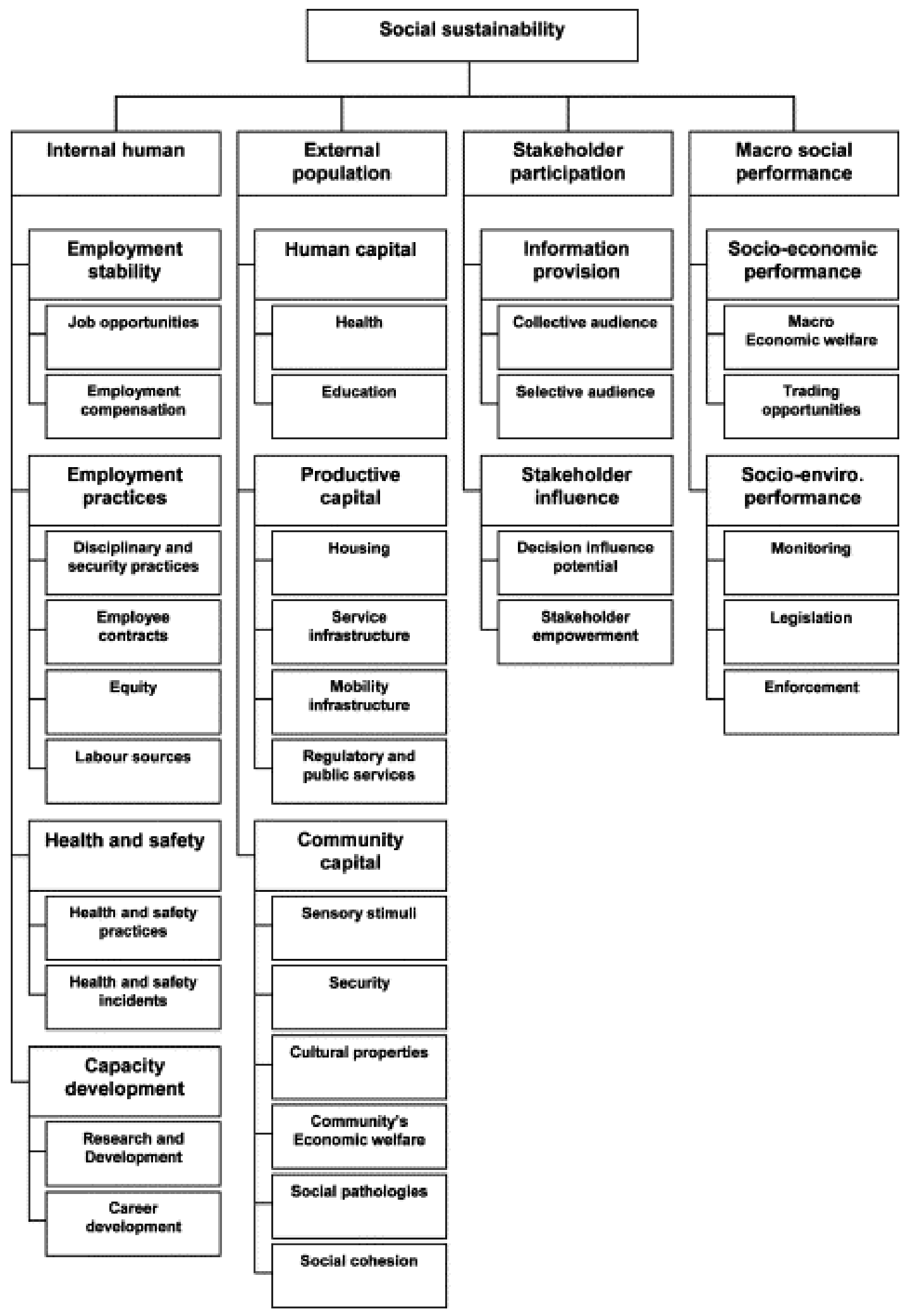

Fig. 6. Breakdown of the sub-criteria of the main social sustainability criterion. 


\subsubsection{Internal human resources}

The internal aspects of social sustainability, excluding internal stakeholder relationship management, are grouped under this criterion. It thus focuses on the company's social responsibility towards its workforce and consists of four sub-criteria:

(a) Employment stability: The criterion addresses a business initiative's impact on work opportunities within the company, the stability thereof as well as evaluating the fairness of compensation.

(b) Employment practices: Disciplinary and secrecy practices as well as employee contracts are addressed under this criterion. These are evaluated to ensure that it complies with the laws of the country, international human rights declaration as well as other human rights and fair employment practice standards. The gender and racial equity inside the company is also addressed under this criterion as well as the legitimacy of labor sourcing practices, e.g. child labor, etc.

(c) Health and safety: The criterion focuses on the health and safety of the workforce and evaluates preventive measures as well as the occurrence and handling of health and/or safety incidents.

(d) Capacity development: The criterion addresses two different aspects, namely research and development, and career development. Research and development evaluates the company's contribution to sustainable product development through its research and development program as well as its innovativeness. Career development focuses on the training of employees and the provision of career guidance and higher-education opportunities.

\subsubsection{External population}

The external dimension of social sustainability is divided between this criterion and the criterion "macro-social performance". External populations focuses on the impact of the company's operations on the community in which it operates, i.e. communities within the close vicinity of any of the company's operations. The criterion consists of three subcriteria:

(a) Human capital: Human capital refers to an individual's ability to work in order to generate an income and encompasses aspects such as health, psychological well-being, 
education, training and skill levels. The criterion addresses health and education separately. Health focuses on the additional strain or beneficiation of a company's activities on local medical facilities. Education considers the impact on education facilities and the effect of possible training opportunities and the sharing of information on the community's level of education.

(b) Productive capital: Productive capital entails the assets and infrastructure an individual needs in order to maintain a productive life. The criterion measures the strain placed on these assets and infrastructure availability by the business initiatives. The following groups are addressed separately: housing; service infrastructure, which entails water and electricity supply as well as sewage and waste services; mobility infrastructure, which considers public transport and the quantity, quality and burden on transport networks, e.g. public roads; and regulatory and public services.

(c) Community capital: This criterion takes into account the effect of an operational initiative on the social and institutional relationships and networks of trust, reciprocity, and support as well as the typical characteristics of the community. Six groups are addressed separately: sensory stimuli (aesthetics, noise and odor levels); cultural properties; social pathologies (induced or increased); security (induced or increased crime); economic welfare (induced business opportunities, impacts on poverty) and social cohesion (networks, demographics and equity aspects). The evaluation of performance in the area of community capital is of utmost importance in evaluating the social sustainability of a project as it has been implied that the core of sustainability is "how people feel about their surroundings and their way of life" [36]. These perceptions can directly influence stakeholder participation initiatives.

\subsubsection{Stakeholder participation}

The treating of stakeholders in an ethically and socially responsible manner has been seen as the core of CSR [37]. Additionally, stakeholder management has been regarded as the tool to connect strategy to social and ethical issues [38]. A separate criterion is thus proposed to assess the relationships between the company and its internal and external stakeholders. The criterion is divided in two sub-criteria: 
(a) Information provision: The quantity and quality of information shared with stakeholders are measured. Information can either be shared openly with all stakeholders (collective audience) or shared with targeted, specific groups of stakeholders (selected audience).

(b) Stakeholder influence: Stakeholder participation has only really succeeded if the stakeholders' opinion is known throughout the company. The company must thus "empower" the stakeholders by ensuring structures to distribute the information. The degree to which the company actually incorporates the stakeholders' opinions into operational decision-making should therefore be evaluated. Two separate groups are included: decision influence potential and stakeholder empowerment.

\subsubsection{Macro-social performance}

The macro-social performance criterion focuses on the company's impact on the external population on a regional and/or national level. The impacts on the economic systems of the region or nation, and therefore the external economic sustainability focus, are addressed under this criterion due to the fact that the economic dimension of the proposed framework only addresses internal aspects. The criterion is divided into two sub-criteria: (a) Socio-economic performance: This criterion addresses the external economic impacts of the company's business initiatives. Economic welfare (contribution to GDP, taxes, etc.) and trading opportunities (contribution to foreign currency savings, etc.) are addressed as separate sub-criteria.

(b) Socio-environmental performance: This criterion considers the contributions of an operational initiative to the improvement of the environment, for the society on a community, regional, and national level. The extension of the environmental monitoring abilities of the society, as well as the enhancement of legislation and the enforcement thereof, are included in this criterion. 


\section{Appropriateness of the proposed framework criteria for project life cycle management in the South African process industry}

A pre-survey has been conducted in the South African process industry to establish the suitability of the framework, as well as the relevance of the criteria in the framework, in terms of sustainable business practices such as project life cycle management. A large petrochemical company in South Africa has been used for the pre-survey. The expertise of the 23 participants (in the company) is summarized in Fig. 7 and consists of professionals who are:

- Actively involved in project management, either during the execution of projects or during project appraisal.

- Responsible for Environment Impact Assessments (EIAs) in the company.

- Involved with CSR projects.

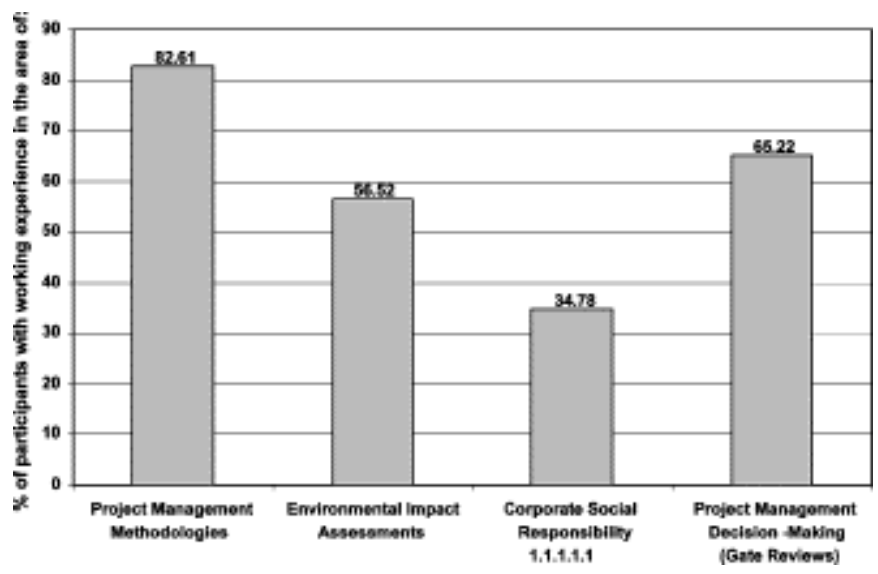

Fig. 7. Related expertise of the participants of the pre-survey in the process industry.

The 23 participants of the pre-survey were requested to rate the relevance of the different criteria in the proposed framework on a scale from 1 to 3, i.e. low, medium, and high. The participants were further required to provide an indication of whether the criteria are represented at the correct level in the framework (Fig. 5 of Section 3.2). The results of the pre-survey are summarized in Table 2. 
Table 2. Pre-survey results of the relevance of the framework criteria for operational (project) sustainability assessment, and the appropriateness of the level of the different criteria in the proposed framework

\begin{tabular}{|c|c|c|c|c|}
\hline Giferta & Releymee & & Gerreet levef (os) & Gexmetris mean \\
\hline & IIs/ (x) & Medium (F) & & \\
\hline Pimaneial bealth & 9180 & a.55 & 8696 & 28 \\
\hline Feonewie performanoc & 7391 & 21.74 & a1.30 & 2,6 \\
\hline Potental finamial benefis: & 26,09 & 65.22 & $\$ 6,96$ & 21 \\
\hline Tradling orpertwifles & 43,48 & $\$ 6.52$ & $\$ 6.96$ & 9.4 \\
\hline Air resaukes & 82,61 & 13.94 & 82.61 & 2,7 \\
\hline Water rescuces & 82. 61 & 17.39 & 8696 & 28 \\
\hline Land weseures & 56.51 & 34.78 & $\$ 696$ & 24 \\
\hline $\begin{array}{l}\text { Minerals and energy re } \\
\text { sowuces }\end{array}$ & 6592 & 34.78 & 86.96 & 26 \\
\hline Insmal human rsoures & 69.57 & 26.09 & $\$ 6.96$ & 26 \\
\hline Employment stabiliny & 47.83 & 43,48 & ถ2. 61 & 2.3 \\
\hline Employwent preatices & 36,69 & 69.57 & 86.96 & 2,2 \\
\hline Hvalth and saley & 82.61 & 17.59 & 5217 & 28 \\
\hline Cupacify dovelogment & 60.87 & 30.43 & 86.96 & 2.4 \\
\hline Exfemal pepulatien & 50.52 & 39.13 & 8696 & 2,4 \\
\hline Hurnan Gapdfal & 69.57 & 26.09 & 78.26 & 26 \\
\hline Produetive eapital & 43.49 & 47.83 & 8261 & 2.3 \\
\hline Community eapital & 26,09 & 49,48 & 82.61 & 18 \\
\hline Stakehrelder participation & $47,8,3$ & 47,83 & 86,96 & 2,4 \\
\hline Infomatîn weyisim & 21.74 & $\$ 6.53$ & 82.61 & 1.9 \\
\hline Spakehoider influenes & 26.09 & 69.57 & 8696 & $2 . ?$ \\
\hline Macro-secial perfomnance & 13,04 & 78.26 & 86.96 & $2 \beta$ \\
\hline $\begin{array}{l}\text { Secie ecsnamis peris } \\
\text { mames }\end{array}$ & 65.93 & 30,43 & 92.61 & 9.5 \\
\hline $\begin{array}{l}\text { Socie-enwirsumental } \\
\text { Performance }\end{array}$ & 39,13 & 56.52 & 8261 & 2.3 \\
\hline
\end{tabular}

The criteria of the economic and environmental dimensions were perceived to be relevant, and the levels thereof are adequate for project assessment purposes. Of the four main social criteria, only the criterion "macro-social performance" was identified as the least relevant to business sustainability. This can, however, be due to the definition used as well as the fact that the criterion is often seen as an economic sustainability criterion. The sub-criteria of “internal human resources”, "stakeholder participation”, and "macrosocial performance” were all received well. An outcome of the pre-survey was that $40 \%$ of the respondents stated that the criterion "health and safety" should manifest on a higher level within the framework. The outcome can be rationalized considering the extensive health and safety campaigns that have been launched in the South African 
process industry over the last two decades [39]. The sub-criteria of the "external population" criterion was not received particularly well, especially the "community capital" criterion, which was deemed not relevant by more than $30 \%$ of the participants. This outcome indicates that the paradigm shift of businesses taking responsibility for their social impacts on external communities have not yet taken place under all role players within the South African process industry. The results of the pre-survey therefore show that some of the criteria definitions may have to be redefined in the structure of an extensive survey in the South African process industry.

\section{Identifying measurable indicators for the proposed criteria}

The identification of suitable indicators to measure the impacts of an operational activity, e.g. an undertaken project, on the three main sustainability dimensions is dependent on the following three important points:

- The kind of information that is available at the point of assessing the sustainability performance of a specific operational activity. For example, considering the life cycle of a technology development project in the process industry, detailed data may not exist in the early stages of the project on which to base an assessment, but may be available at later decision gates in the project appraisal process.

- The scientific methodology to translate the operational activity information. Section 3.4 highlighted that there is currently no consensus on the exact procedure to assess the environmental performances of operational activities. However, work is ongoing in this field and methodologies have been proposed. With respect to the social dimension, there is little agreement on which criteria should be considered for social performance evaluations and methodologies are currently not practical for industry applications and business practices. In contrast, the methodologies for most of the sub-criteria of the economic dimension are reasonably well defined.

- The preferences of the specific assessors and decision-makers of sustainability performances in industry. Two approaches are currently under debate, as is shown in Fig. 8. On the one hand all impacts could be translated into financial terms [40], which is 
often understandable by decision-makers. On the other hand, it is difficult, if not impossible, to place an economic value on all environmental and social impacts [41], and a qualitative route with decision analysis techniques, e.g. Multi-Criteria Decision Analysis (MCDA), could be used [42]. In some cases, a combination of these two approaches have been proposed [43].

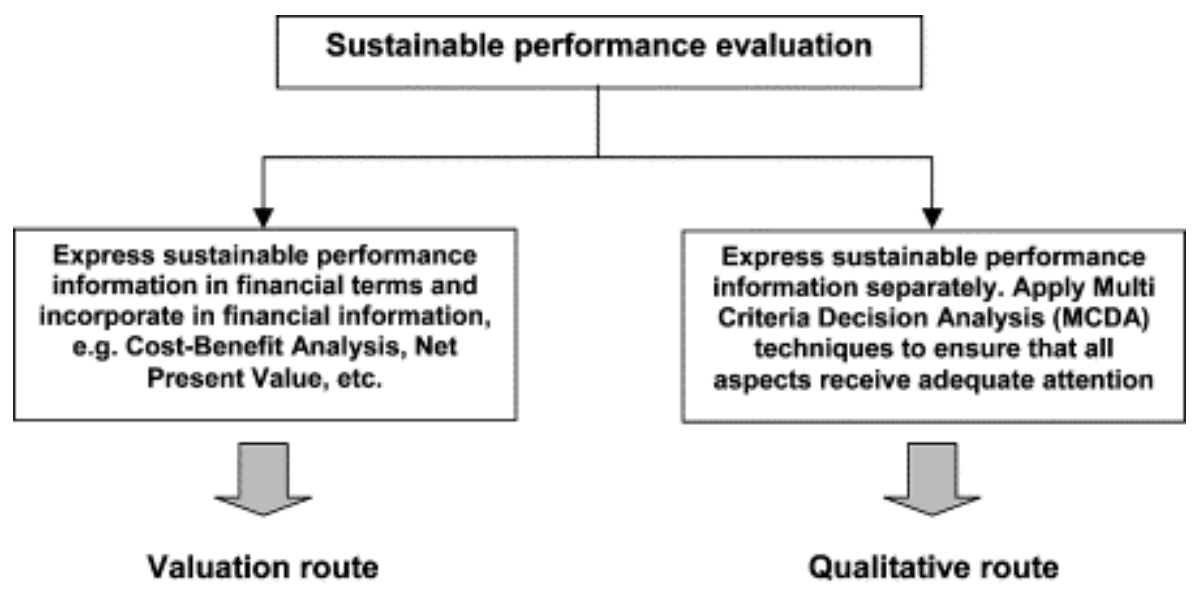

Fig. 8. Possible methodologies to incorporate sustainability performance aspects into decision-making.

Based on these points, it is considered that the integration of the existing and developed methodologies should be used in order to derive suitable indicators to measure sustainability performances of operational activities. Furthermore, the overall procedure (and subsequent indicators) would, most probably, be company-specific.

\section{Conclusions and the way forward}

A framework is proposed to assess the sustainability performances of a company and its operational activities. The criteria addressed in the proposed framework are particularly applicable to assess projects that are undertaken in the process industry. Separate productspecific criteria have been omitted from the framework since products, as the core output of industry activities, should be subjected to the same sustainability assessment process. The proposed framework can thus be used to establish the sustainability of the products as well. An extensive survey is underway in the South African process industry to 
establish the respective weighting values (and subsequent relative importance) of the different criteria in the proposed framework for overall sustainability performances. The weighting values will be based on the perceptions of (project) decision-makers in the South African process industry.

A specific set of indicators is also under development for the criteria in the framework that is appropriate for the intended application of project management in a specific company. Although individual indicators may be similar, the overall set of indicators to assess company, project and technology sustainability, would typically be dissimilar. A combination of monetary valuation and MCDA techniques is further evaluated to integrate sustainability assessment results into decision-making practices.

\section{References}

1. W.A.M.-T. Visser, Sustainability reporting in South Africa. Corporate Environmental Strategy 91 (2002), pp. 79-85.

2. Deloitte \& Touche, ISSD. Business strategy for sustainable development: leadership and accountability for the 90s. IISD, 1992.

3. H. Briassoulis, Sustainable development and its indicators: through a (planner's) glass darkly. Journal of Environmental Planning and Management 443 (2001), pp. 409-427. 4. K.-H. Robèrt, B. Schmidt-Bleek, J. Aloisi de Larderel, G. Basile, J.L. Jansen, R. Kuehr et al., Strategic sustainable development—selection, design and synergies of applied tools. Journal of Cleaner Production 10 (2002), pp. 197-214.

5. K. Hockerts, The sustainability radar: a tool for the innovation of sustainable products and services. Greener Management International 25 Spring (1999), pp. 29-49.

6. Warhurst A. Sustainability indicators and sustainability performance management. Mining, Minerals, and Sustainable Development March 2002; no. 43.

7. United Nations Commission on Sustainable Development. Indicators of sustainable development: guidelines and methodologies. United Nations, 2001; Available from: http://0-www.un.org.innopac.up.ac.za:80/esa/sustdev/natlinfo/indicators/indisd/indisdmg2001.pdf. 
8. Hass JL, Brunvoll F, Hoie H. Overview of sustainable development indicators used by national and international agencies. Paris: OECD Statistics Working Paper 2002/1, 2002. 9. V. Veleva and M. Ellenbecker, A proposal for measuring business sustainability: addressing shortcomings in existing frameworks. Greener Management International 31 Autumn (2000), pp. 101-120.

10. Ranganathan J. Sustainability rulers: measuring corporate environmental and social performance. Sustainable enterprise perspectives. Washington DC: World Resource Institute, May 1998; Available from: http://www.igc.org/wri/meb/pdf/janet.pdf/. 11. J. Ranganathan, Signs of sustainability. In: M. Benett and P. James, Editors, Sustainable measures: evaluation and reporting on environmental and social performance, Greenleaf Publishing, Sheffield (1999), pp. 475-495.

12. GRI. Sustainability reporting guidelines, Global Reporting Initiative, Boston (MA) (2002).

13. IChemE. The sustainability metrics: sustainable development progress metrics recommended for use in the process industries, Institution of Chemical Engineers, Warwickshire (2002).

14. Labuschagne C. Sustainable project life cycle management: criteria for the South African process industry. Master's thesis, Department of Industrial and Systems Engineering, University of Pretoria, February 2003.

15. Spangenberg JH, Bonniot O. Sustainability indicators—a compass on the road towards sustainability. Wuppertal Paper No 81, February 1998.

16. J.H. Spangenberg, S. Pfahl and K. Deller, Towards indicators for institutional sustainability: lessons from an analysis of Agenda 21. Ecological Indicators 21-2 (2002), pp. 61-77.

17. J. Nelson, Corporate social responsibility: passing fad or fundamental to a more sustainable future?. Sustainable Development 7 (2002), pp. 37-39.

18. Caux Round Table. Principles for business. Retrieved from the World Wide Web on 20 January 2003 from: http://www.cauxroundtable.org/ENGLISH.htm/.

19. G. Fenwick, Social reach: guidelines for effective community involvement. People Dynamics 115 (1993), pp. 20-22.

20. E. Bickham, Corporate responsibility. Optima 481 (2002), pp. 32-51. 
21. Republic of South Africa. National Environmental Management Act no 107 of 1998. Government Gazette 1998; 19519.

22. Heuberger R. CDM projects under the Kyota protocol of the UNFCCC: a methodology for sustainable development assessment and an application in South Africa. Diploma Thesis submitted to Institute of Environmental Physics, Energy \& Climate Swiss Federal Institute of Technology (ETH). Zurich, 2003.

23. A.C. Brent, A proposed lifecycle impact assessment framework for South Africa from available environmental data. South African Journal of Science 99 March/April (2003), pp. 115-122.

24. X. Olsthoorn, D. Tyteca, W. Wehrmeyer and M. Wagner, Environmental indicators for business: a review of the literature ad standardization methods. Journal of Cleaner Production 95 (2001), pp. 453-463.

25. A. Azapagic and S. Perdan, Indicators of sustainable development for industry: a general framework. Trans IChemE 78 B (2000), pp. 243-261.

26. UNEP, SETAC. Global life cycle initiative. Available from: http://www.uneptie.org/pc/sustain/lcinitiative/, accessed on 8 October 2003.

27. C.O. Holliday, S. Schmidheiny and P. Watts. Walking the talk: the business case for sustainable development, Greenleaf Publishing, Sheffield (2002).

28. W. Visser and C. Sunter. Beyond reasonable greed: why sustainable business is a much better idea, Human \& Rousseau Tafelberg, Cape Town (2002).

29. European Commission. Promoting a European Framework for CSR Green paper. Luxembourg: Office for Official Publications of the European Communities, 2001. 30. Interorganizational Committee on Guidelines and Principles for Social Impact Assessment, Guidelines and principles for Social Impact Assessment. Environmental Impact Assessment Review 15 (1995), pp. 11-43.

31. Vine E, Sathaye J. Guidelines for the monitoring, evaluation, reporting, verification and certification of energy-efficiency projects for climate change mitigation. U.S. Environmental Protection Agency through the U.S. Department of Energy under Contract No. DE-AC03-76SF00098, 1999. 
32. South Sydney Council. Social Impact Assessment Checklist. Retrieved from Worldwide web on 22/2/2003 from: http://0www.sscc.nsw.gov.au.innopac.up.ac.za:80/images/upload/DCP_H.pdf/.

33. M. Khosa, Social Impact Assessment of development projects. In: M. Khosa, Editor, Infrastructure mandate for change 1994-1999, Human Sciences Research Council (HSRC) Publishers, Pretoria (2000).

34. F. Vanclay, Conceptualising social impacts. Environmental Impact Assessment Review 22 (2002), pp. 183-211.

35. I. Knoepfel, Dow Jones Sustainability Group Index: a global benchmark for corporate sustainability. Corporate Environmental Strategy 81 (2001), pp. 6-15.

36. R. Levett, Sustainability indicators - integrating quality of life and environmental protection. Journal of the Royal Statistics Society 1613 (1998), pp. 291-302.

37. M.J.D. Hopkins, Sustainability in the internal operations of companies. Corporate Environmental Strategy 94 (2002), pp. 398-408.

38. S.L. Wartick and D.J. Wood, Editors, International business and society, Blackwell, Malden (MA) (1998).

39. Z. Issacs, Focus on health and safety intensifying. Engineering News 2337 (2003) p. 52, 58 .

40. Van Erck R. A monetary evaluation of the sustainability of GTL fuel production in South Africa. Master's thesis, Faculty of Technology Management, Technical University Eindhoven, October 2003.

41. R. Jansen. Multi-objective decision support for environmental management, Kluwer Academic Publishers, Dordrecht (1992).

42. J. Petrie, L. Basson, M. Stewart, P. Notten and B. Alexander, Decision making for design of cleaner processes: a life cycle management perspective. In: (2001). 43. J.T. Winpenny. Values for the environment: a guide to economic appraisal, HMSO, London (1991).

Corresponding author. Tel.: +27-12-420-3929; fax: +27-12-362-5307. 